\title{
Spinal Cord Infarction
}

National Cancer Institute

\section{Source}

National Cancer Institute. Spinal Cord Infarction. NCI Thesaurus. Code C99063.

Ischemic necrosis of the spinal cord caused by occlusion of the arteries that supply blood to the spinal cord. Signs and symptoms include intermittent back pain, pain in the legs, paralysis, and incontinence. 